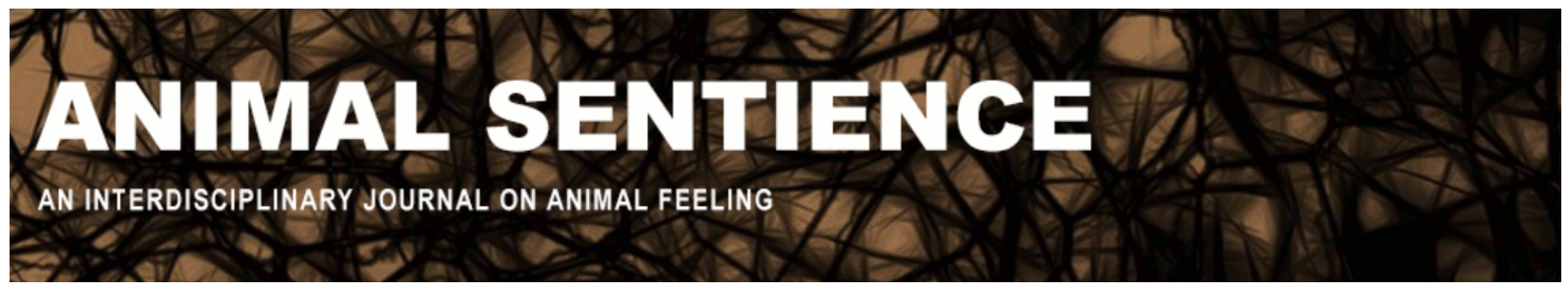

Gupta, Rupu (2019) Just preservation: From vision to reality. Animal Sentience 27(9)

DOI: $10.51291 / 2377-7478.1538$

Date of submission: 2019-12-07

Date of acceptance: 2019-12-13

(c)

This article has appeared in the journal Animal

Sentience, a peer-reviewed journal on animal

cognition and feeling. It has been made open access,

free for all, by WellBeing International and deposited

in the WBI Studies Repository. For more information,

please contact

wbisr-info@wellbeingintl.org.

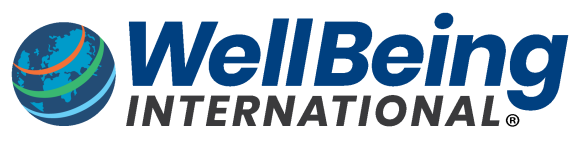

SOLUTIONS FOR PEOPLE, ANIMALS AND ENVIRONMENT 


\title{
Just preservation: From vision to reality
}

Commentary on Treves et al. on Just Preservation

\author{
Rupu Gupta \\ Researcher, Knology
}

\begin{abstract}
Treves et al. propose a tangible shift in current discourse and practice related to the human relationship with other forms of nature. They aim to instill an ethical stance in human perspectives on nature, advocating the idea of trustees as advocates for non-human nature in consensus-building scenarios. This commentary raises questions about the practicality of a widescale culture shift in values towards non-human nature, and the power dynamics that are inevitable in multi-stakeholder settings.
\end{abstract}

Rupu Gupta is a conservation psychologist with expertise in inclusive practices in the environmental movement and culturally responsive approaches. She leads Knology's Biosphere research. Her current research includes studying the environment as a pathway to learning STEM in informal and formal contexts. Website

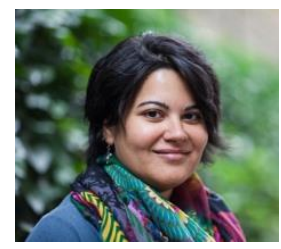

Treves et al. $(2018,2019)$ champion a cause that many in the conservation and environmental sectors may endorse in theory but that suffers from anthropocentrism in its myriad forms. The authors' discussion of the number of ways anthropocentrism manifests itself reinforces that much work is needed in the conservation sphere to ensure the wellbeing of the "community of life". As they bring to the forefront the intrinsic value of non-human beings, in parallel with that of humans, they articulate a well-reasoned treatise, with implications for practice and discourse, at least in the fields and sectors mentioned above. From the perspective of a conservation psychology that aims to understand human motivations and barriers to care for nature in all its forms, a key next step will be to understand the "who", "why", and "how" that will make "just preservation" a reality. The following sections describe some of the questions and concerns raised as we consider the phenomenology of the human experience.

Ethics towards non-human nature. Treves et al. provide strong arguments for instilling an ethic of justice toward non-human nature, given how prevalent the disregard of their wellbeing is in practice. This is further bolstered by an expansive self-concept the authors call out by emphasizing "other selves" who are part of the community of life, where humans also belong. The caveat here is that it is probably unrealistic to expect endorsement of this strong moral stance beyond subsections of those in the conservation, environmental, natural resources, and related sectors. Indeed, humans accord moral reasoning to non-human nature typically in relation to the extent to which their own needs and priorities are met (Clayton \& Myers, 2015). For example, when human interests conflict with those of wild animals, concern for their wellbeing diminishes (Kellert, 1996). Surveys of the American public suggest that people hold utilitarian values towards 
wildlife simultaneously with mutualist values that support coexistence in harmony (Manfredo et al., 2018). All this is to highlight that if Treves et al. wish to engage members of the public in this dialogue, they will need to appreciate public perspectives on the human relationship with other forms of nature.

Multi-stakeholder engagement in the environmental field. The notion of trustees as advocates for non-human life is ambitious, but necessary, to shift the current paradigm. Of note is the acknowledgement that multiple stakeholders need to be part of a consensus-building process, where trustees represent the voice of the disenfranchised, in this case, non-human nature. Such inclusive approaches are of critical value in the environmental field, where stakeholders with different worldviews strive to work together across philosophical boundaries (Gupta, Ardalan, \& Fraser, 2017). Cultural competence in relation to conceptualizing nature and the environment suggests that there are diverse views on what nature means (Gupta, Fraser, \& Rank, 2014). Representation and inclusion are prerequisites for moving toward a shared, superordinate goal. But the question arises: do trustees, as Treves et al. describe, initiate this process, or is the call for others to include them in the process? Irrespective of the answer to this question, the point is that unequal power dynamics will be a pronounced feature of these interactions, with the potential to stymie the minority view (in the case of trusteeship, that of the advocates for nonhuman beings), unless the meetings are strategically planned and managed. To move Treves et al.'s vision to reality, the suggestion is to give strong consideration to who is at the table, who is not, and to prepare to manage rich but emotionally challenging dialogue.

\section{References}

Clayton, S., \& Myers, G. (2015). Conservation psychology: Understanding and promoting human care for nature. John Wiley \& Sons.

Gupta, R., Ardalan, N., \& Fraser, J. (2017). The intergroup context of environmental education and approaches to facilitate collaboration. Small Group Research, 48(4), 420-454.

Gupta, R., Fraser, J., \& Rank, S. J. (2014). Development of staff cultural capacity in an intensive environmental stewardship program for urban youth. Environmental Management and Sustainable Development, 3(2), 182-205.

Kellert, S. R., Black, M., Rush, C. R., \& Bath, A. J. (1996). Human culture and large carnivore conservation in North America. Conservation Biology, 10(4), 977-990.

Manfredo, M. J., Sullivan, L., Don Carlos, A. W., Dietsch, A. M., Teel, T. L., Bright, A. D., \& Bruskotter, J. (2018). America's Wildlife Values: The Social Context of Wildlife Management in the U.S. National report. Fort Collins, CO: Colorado State University, Department of Human Dimensions of Natural Resources.

Treves, A., Santiago-Ávila, F. J., \& Lynn, W. S. (2018). Just preservation. Biological Conservation, 229, 134-141.

Treves, A., Santiago-Ávila, F. J., \& Lynn, W. S. (2019) Just preservation. Animal Sentience 27(1). 